\title{
Experimental Studies on Thermo-Physical Properties of Nanocellulose-Aqueous Ethylene Glycol Nanofluids
}

\author{
K. Farhana ${ }^{1,2}$, K. Kadirgama ${ }^{1, *}$, D. Ramasamy ${ }^{1}$, M. Samykano ${ }^{1}$, G. Najafi ${ }^{3}$ \\ 1 Faculty of Mechanical Engineering, Universiti Malaysia Pahang, 26600 Pekan, Pahang, Malaysia \\ Department of Apparel Manufacturing Engineering, Bangladesh University of Textiles, Dhaka 1208, Bangladesh \\ Tarbiat Modares University, Tehran, Iran
}

\section{ABSTRACT}

The aim of this experimental research study is to evaluate the thermal behaviour of crystal nanocellulose (CNC) nanofluids. Aqueous ethylene glycol (60: $40 ; \mathrm{W}$ : EG) used as base fluid and $0.1 \%, 0.3 \%$ and $0.5 \%$ volume concentrations were designated here. Crystal nanocellulose nanofluids were prepared by two-step method. Thermal conductivity, viscosity, density, specific heat capacity and $\mathrm{pH}$ were assessed with standard measurement method and equipment. In this present work, thermal conductivity of $0.3 \%$ CNC nanofluids was increased of about $25 \%$ at $80^{\circ} \mathrm{c}$; viscosity decreased; $0.1 \%$ nanofluid exhibit lowest viscosity performance at $80^{\circ} \mathrm{c}$. In addition to this, $0.5 \% \mathrm{CNC}$ nanofluid performed better declination of specific heat with increasing temperature up to $70^{\circ} \mathrm{C}$ and lowest error percentage in density measurement. However, some data of the experiments were distracted.

\section{Keywords:}

Crystal Nanocellulose; Thermal

Conductivity; Viscosity; Density; Specific

\section{Introduction}

Needs and luxury of human being both completely depends on energy, as energy is the lifeboat of modern world. Today's dramatic rising trend of energy consumption which is making a conflict among national and international community and with that global climate change challenge is now a crucial issue [1-2]. To bypass the energy scarcity and to secure the energy supply, a stable and sustainable source of energy is highly demandable. In this respect, technology and innovation can play a vital role by increasing global energy security [3]. Moreover, energy is the fundamental input to economic activities and therefore human success \& social developments entirely depends on it. Besides, energy is the major part of industrialization as technological improvement, productivity and production enhancement, mechanizing and automation, technique and information exchange through industrial sector to the globe [4-6]. Today global energy supply depends over $80 \%$ on fossil fuel [7]. Due to depletion and negative impact on to the environment; it is fire urgent to take necessary actions to resolve these problems. In this circumstance, alternative of fossil fuels or

\footnotetext{
* Corresponding author.

E-mail address: kumaran@ump.edu.my
}

https://doi.org/10.37934/arms.69.1.115 
renewable energy is inevitable [8]. Renewable energies are generally eco-friendly [9] and obtained from those resources which are essentially inexhaustible and abundant [10]. Today nano technology is attracting more attention of many researchers to solve different problems in different field such as physics, chemistry, engineering, biology etc. In respect of fluid mechanics, nanofluid can be used associated with thermal energy enhancement properties [11]. Nanofluid is the fluid with nano sized solid particles which may be metallic or non-metallic solid particles can change the transport properties and heat transfer characteristics of the base fluid [12-13]. Thermal conductivity and heat transfer coefficient increases with increase in volume fraction and mass flow rate of nanofluids [1415].

Though, nanoparticle is the most auspicious and important invention for today's science and engineering field, it also has some adverse effects such as possible toxicity of nanoparticles towards the environment which poses the potentiality of hazardous substances for plants and human health as well. In recent studies mentioned that nanotoxicity of metal oxide particles especially oxidative stress-introduced the flow that directs the inflammatory responses. Besides, researchers investigated that there should be ecological problem when plants would be captivated by nanoparticles and as a result human being may be attacked [16-20]. Therefore as an alternative, over the last few years nano cellulose attract more attention of the researchers due to their some impressive characteristics such as biodegradability, excellent mechanical properties, low density, availability of renewable resources and most significantly eco-friendly attribute as well [21-23]. Nanocellulose manufactured from wood-based cellulose and mainly in two groups such as cellulose nanofibrils (CNF) and cellulose nanocrystal (CNC). Generally CNC is formed by hydrolysing the amorphous region of cellulose with acid and then followed by centrifugation, dialysis and sonication and then finally crystal nanocellulose produced [24-25]. Theoretically crystalline region in nanocellulose is stabilized by hydrogen bonds between hydroxyl groups. Therefore, nanocellulose has higher strength and stiffness in structure. Some literatures mentioned nanocellulose has good mechanical properties as well [26-27].

The aim of this research study is to evaluate different thermal properties of crystal nanocellulose nanofluid based on aqueous ethylene glycol (60: 40; W: EG) with various volumetric concentrations. Therefore, nanofluid preparation, measurement of different thermal properties such as thermal conductivity, viscosity, density, stability, $\mathrm{pH}$ and specific heat capacity have been done followed by comparing the resulting data with standard data and statistical analyses.

\section{Experimental Method and Materials}

\subsection{Nanofluid Sample Preparation}

Nanofluid preparation is the first and fundamental step of any kind of nanofluid experimental studies. The crystal nanocellulose used in this study purchased from Blue Goose Biorefiners Inc. supplier. The specification of CNC has been presented in Table 1 which was provided by the supplier and density of CNC nanoparticles is around 1.5-1.6 g/ $\mathrm{cm}^{3}$ [28]. Transmission Electron Microscope (TEM) used for the microstructural characterization of CNC nanofluids. TEM images of CNC nanofluids at $X 50,000$ and $X 100,000$ shown in Figure 1. Images showed the average size of CNC nanoparticles is 41-137 nm. Here two step method of nanofluid preparation used. The nanocellulose was dispersed in the base fluid (60 water: 40 ethylene glycol ratio) at various volume concentrations such as $0.1 \%$, $0.3 \%$ and $0.5 \%$. The required mass of nanocellulose corresponding to the volume concentration was calculated in Eq. (1) [29] and weighed utilizing a high precision (0.0001 g) electronic balance. 


$$
V 0 l \%=\frac{W_{n p}{ }^{\prime} \rho_{n p}}{W_{n p} \rho_{n p}+V_{b t}}
$$

The samples were stirred for good mixing by using magnetic stirrer for half an hour. Finally, to produce highly stable and homogenous nanofluids, the mixed samples placed in ultrasonic processor for $1 \mathrm{~h}$. named Fisherbrand model number-FB1505 which is similar equipment conducted by several researchers previously in experimental studies [30-31].

Table 1

Specification parameters of CNC [32]

\begin{tabular}{ll}
\hline Parameter & Value \\
\hline Crystallinity index & $80 \%$ \\
Crystal length & $100-150 \mathrm{~nm}$ \\
Crystal diameter & $9-14 \mathrm{~nm}$ \\
Hydrodynamic Diameter & $150 \mathrm{~nm}$ \\
\hline
\end{tabular}

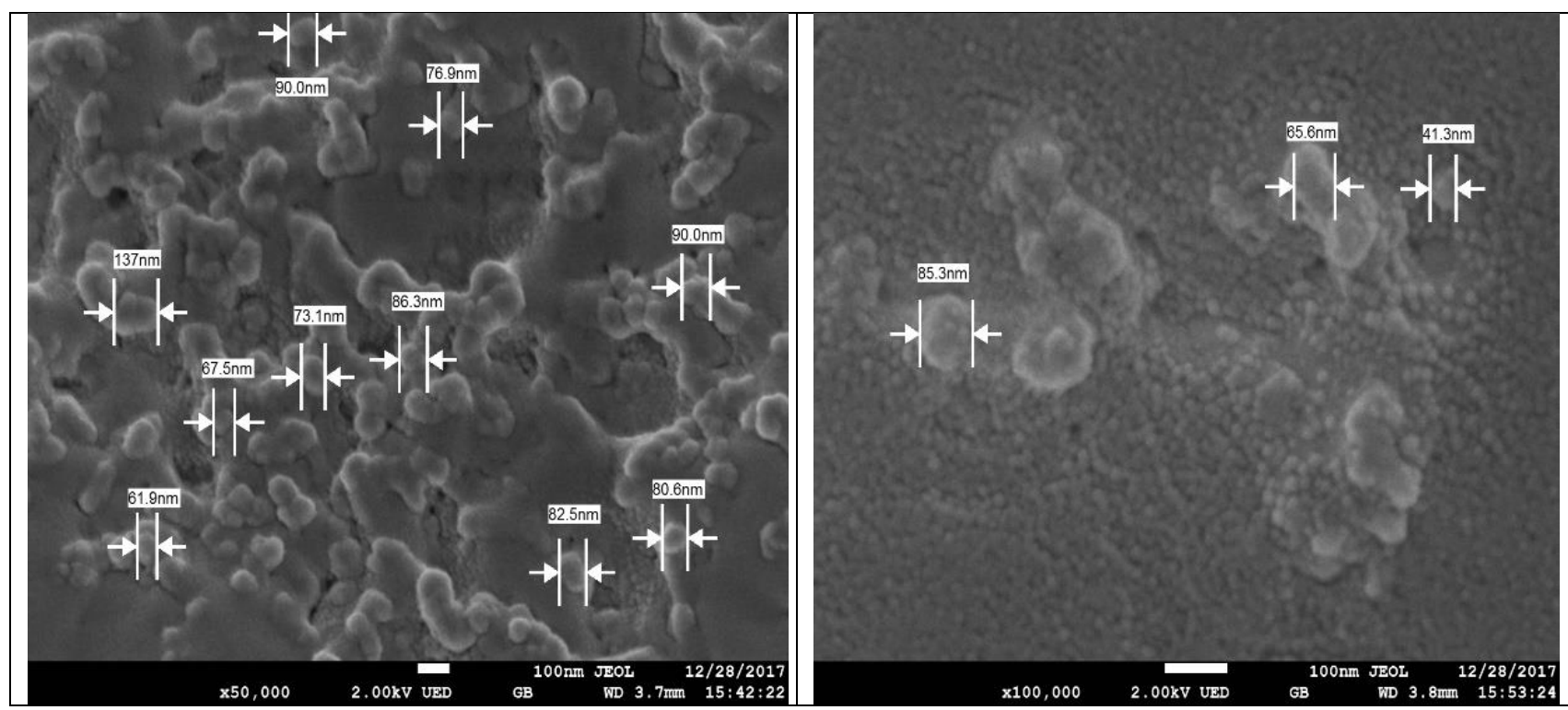

Fig. 1. TEM images of $X 50,000$ and $X 100,000$ magnification of $C N C$ nanofluids

\subsection{Measurement of Thermal Conductivity}

Thermal conductivity of base fluid and CNC-nanofluid at various concentrations was measured by Thermal Property Analyser (Decagon Devices, Inc., USA). The transient hot-wire method was the operating principle of that device. KD2 Pro consists of a handheld controller and a sensor. Here 60 $\mathrm{mm}$ long with $1.3 \mathrm{~mm}$ diameter single-needle KS-1 sensor used in accordance with test sample to measure thermal conductivity. This sensor can measure the thermal conductivity in between 0.002 $2.00 \mathrm{~W} / \mathrm{m}-\mathrm{k}$ with an accuracy of $\pm 5 \%$. The experiment was performed at a temperature between 30 ${ }^{\circ} \mathrm{C}$ to $80{ }^{\circ} \mathrm{C}$ (controlled condition). Memmert water bath with an accuracy of $0.1{ }^{\circ} \mathrm{C}$ used to maintain the temperature by electric current supplied. The sensor is inserted into the test sample bottle and the bottle is immersed into the water bath. To prevent the bending of sensor, it must be installed in vertical with the cap of bottle. Before starting the actual sample measurement, the sensor was validated by measuring the thermal conductivity of glycerine $\left(k=0.282 \mathrm{~W} / \mathrm{m}-\mathrm{k}\right.$ at $\left.20{ }^{\circ} \mathrm{C}\right)$; solution provided by the manufacturer. Moreover, the thermal conductivity measurement verified by 
measuring the base fluid (60\% water and $40 \%$ ethylene glycol) and compared with predetermined values of ASHREE standard (American Society of Heating, Refrigerating and Air Conditioning Engineers). The maximum deviation between base fluid and ASHREE data was $3.2 \%$. The deviation result determines the authenticity of the Analyser to perform the measurement. Each reading was measured with 15-minute interval time for the consistency of the data. To ignore experimental error, 20-time measurement readings and average did for every concentration of the sample. Previously many researchers used KD2 Pro Thermal Property Analyser to measure the thermal conductivity of nanofluids in experimental studies [33-36].

\subsection{Measurement of Dynamic Viscosity}

Dynamic viscosity of nanofluids was measured with various volume concentrations at a temperature range of $30^{\circ}$ to $80^{\circ} \mathrm{C}$. A Brookfield RST, Coaxial Cylinder rheometer used in this study. RST coaxial cylinder rheometer is connected to a circulating water jacket for considering the temperature range (stipulated temperature range of $30^{\circ}$ to $80^{\circ} \mathrm{C}$ ) along with other purposes used. Rheometer is capable for measuring viscosity range of 0.0001 to $5.4 \times 10^{6} \mathrm{~Pa}$. $s$ and temperature range of $-20^{\circ}$ to $+180^{\circ} \mathrm{C}$. Experiment done under steady state condition. The method of measuring was Rotational measurement under controlled shear rate (CSR) and shear rate was 260 (1/s). To validate the rheometer, the viscosity of base fluid was measured and then compared the obtained values with predetermined data of ASHREE standard. The fluid amount of $15.7 \mathrm{ml}$ is required to measure the viscosity and the reading is assembled in computer connected with RST rheometer. Here twenty times reading obtained and averaged to minimize the experimental error. Earlier several studies conducted viscosity measurement using the Brookfield rheometer [37-39].

\subsection{Measurement of Specific Heat}

Differential Scanning Calorimetry (DSC) is a highly sensitive technique can be used to measure the specific heat capacity of both solid and fluids [40-41]. In this study DSC (model DSC 8000) also used for measuring the specific heat manufactured by PerkinElmer, Inc. Specific heat capacity has been evaluated of base and $\mathrm{CNC}$ nano fluids at a temperature range of $25^{\circ}$ to $90{ }^{\circ} \mathrm{C}$ to get the actual values of specific heat at $30^{\circ}, 50^{\circ}, 70^{\circ}$ and $80^{\circ} \mathrm{C}$ temperature. DSC 8000 is double-furnace thermal analyser and temperature range of $-180^{\circ}$ to $750^{\circ} \mathrm{C}$. Measurement solution was taken in an aluminium pan weighed on electrical balance (precision: 0.0001) and covered with a lid (aluminium) and then sealed by universal crimper press. Prior to actual sample measurement an empty pan/lid and the pan/lid filled with sapphire reference were placed in DSC to obtain the data of baseline and reference. Afterwards the sample pan/lid was mounted in DSC with an empty pan/lid as a reference. Then the temperature range was set with $10^{\circ} \mathrm{C} / \mathrm{min}$ temperature gradient following the standard DSC test method ASTM-E1269. Required time was around $6 \mathrm{~min}$ for every sample. This test has been done for all volume concentrations of nanofluid and base fluid. The resulting values are collected in a computer connected with DSC. Previously many researches used DSC for conducting the specific heat measurement test of nanofluids [42-43].

\subsection{Measurement of Density}

Density is an influential property of nanofluids which affects the pumping power, friction factor, Reynolds number and so no. In this study, to measure the density of CNC nanofluids with different volume concentrations digital density meter used alike with previous studies of various researchers 
[44-46]. Here KEM (model DA-640) density meter manufactured by Kem Kyoto Electronics Co. Ltd. used. This meter has density $\left(\mathrm{gm} / \mathrm{cm}^{3}\right)$ measuring range of $0.0000-3.000$ with $\pm 0.0001 \mathrm{gm} / \mathrm{cm}^{3}$ accuracy and density $\left(\mathrm{gm} / \mathrm{cm}^{3}\right)$ repeatability is 0.00005 . The ambient condition for using this meter is about temperature range of $5-35{ }^{\circ} \mathrm{C}$ and humidity $85 \% \mathrm{RH}$ or below. The method for measuring the density follows ASTM D4052-18 which is acknowledged as Standard test method for density, relative density and API gravity of liquids by digital density meter.

\subsection{Measurement of $\mathrm{pH}$}

For the measurement of $\mathrm{pH}$ of $\mathrm{CNC}$ nanofluids with different volume concentration $\mathrm{pH}$ meter used. A considerable number of experimental studies utilized $\mathrm{pH}$ meter to assess the $\mathrm{pH}$ of nanofluids [47-48]. Here Mettler Toledo $\mathrm{pH}$ meter used (model five easy) to measure the $\mathrm{pH}$ of CNC nanofluids along with base fluid. The $\mathrm{pH}$ measurement range of $\mathrm{pH}$ meter is $0-14$ with accuracy of \pm 0.1 and $\mathrm{pH}$ resolution is 0.01 . The method for evaluating the $\mathrm{pH}$ follows the electrometric method that is APHA $4500 \mathrm{H}^{+} \mathrm{B}$. The basic principle of this electrometric method is to determine the activity of the hydrogen ions by potentiometric measurement using standard and reference electrode.

\section{Results and Discussion}

\subsection{Stability Analysis of CNC Nanofluids}

Sedimentation observation (Qualitative method) has been done to examine the stability of CNC nanofluids at various volume concentrations such as Kadirgama et al., [28] conducted the qualitative method to measure the stability of nanofluids in thermal analysis of SUS 304 stainless steel using nanocellulose/ethylene glycol based study. The sedimentation observed after each fifteen day. No aggregation of CNC nanoparticles occurred at the bottom of test tube even after forty-five days of nanofluids preparation. This observation demonstrates the high stability of nanofluids. Whereas aggregation or clogging of nanoparticles degrades the thermal properties such as thermal conductivity, density, viscosity, specific heat capacity as stability of nanofluids has significant effect on thermal conductivity directly or indirectly [49].

Furthermore, UV-vis spectrum of nanofluids at $0.1 \%, 0.3 \%$ and $0.5 \%$ vol. concentration formed for stability measurement and showed in Figure 2. This is done by UV-Vis Spectrometer (Perkin Elmer Limited, UK). From this spectrum, it can be detected that the peak value of absorbance for all samples lies in the range of $231-233 \mathrm{~nm}$ of wavelength [50].

\subsection{Thermal Conductivity Analysis of Nanofluids}

The thermal conductivity of base fluid ( $60 \%$ water and $40 \% \mathrm{EG}$ ) and CNC nanofluids with different volume concentration $(0.1 \%, 0.3 \%$ and $0.5 \%)$ measured at four different temperature such as $30^{\circ}$, $50^{\circ}, 70^{\circ}$ and $80^{\circ} \mathrm{C}$. Figure 3 shows the thermal conductivity synopsis of base fluid and various volume concentrated CNC nanofluids. 


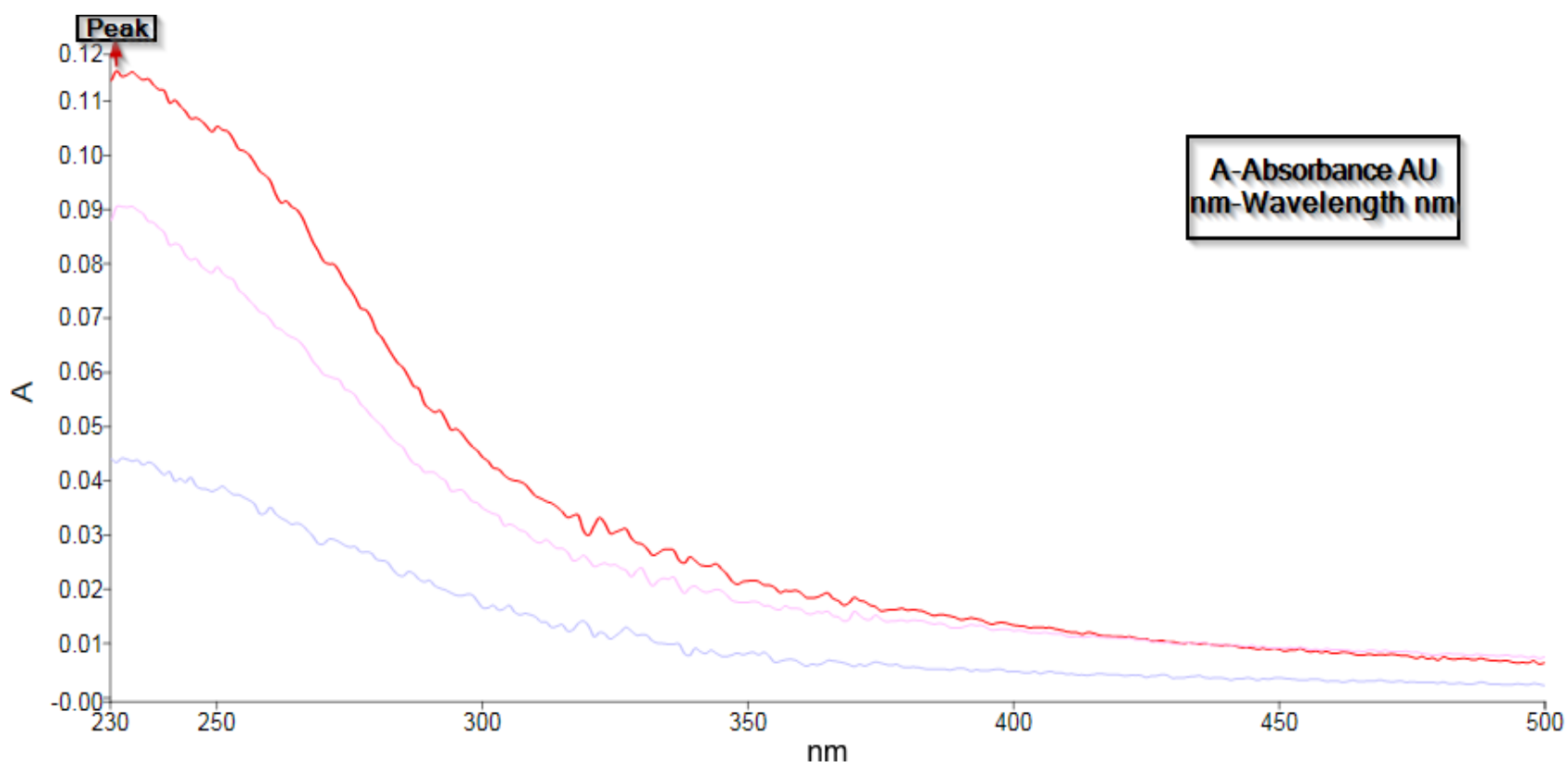

$0.5 \mathrm{CNC}(60 \%$ water $+40 \% \mathrm{EG})$.Sample $0.1 \mathrm{CNC}(60 \%$ water $+40 \%$ EG).Sample liquid $0.3 \mathrm{CNC}(60 \%$ water $+40 \%$ EG) Sample

Fig. 2. UV-vis spectrum for CNC nanofluids

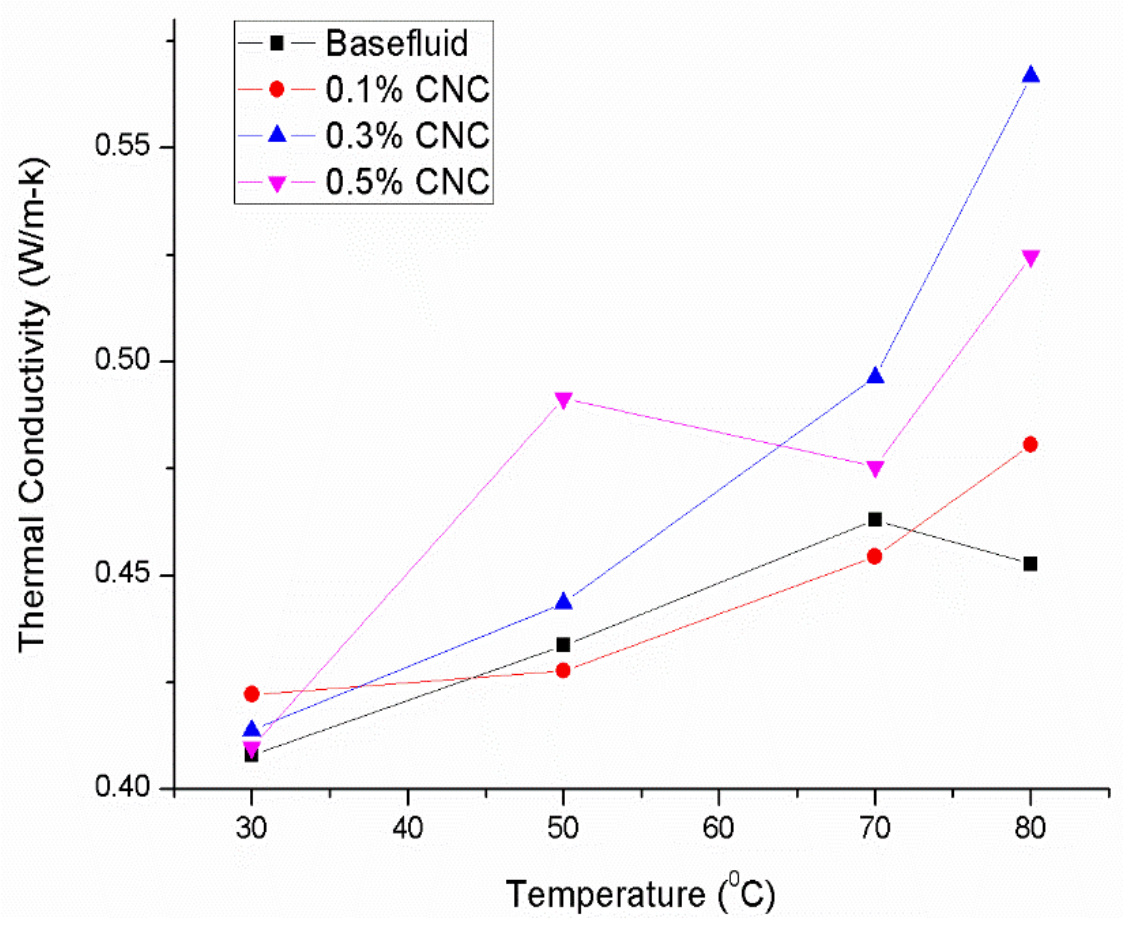

Fig. 3. Thermal conductivity of CNC nanofluids at different temperatures

The result revealed that thermal conductivity of $0.1 \% \mathrm{CNC}$ nanofluids increased more than other two volume fraction of nanofluids and base fluids at $30{ }^{\circ} \mathrm{C}$. Besides, thermal conductivity surged highly for $0.5 \%$ volume concentration CNC nanofluid at $50{ }^{\circ} \mathrm{C}$. In addition, thermal conductivity improved in maximum at $80^{\circ} \mathrm{C}$ for $0.3 \% \mathrm{CNC}$ nanofluid. Moreover, all volume concentration of CNC nanofluids show the increasing trend at $80^{\circ} \mathrm{C}$ temperature, while base fluid shows the downward trend of thermal conductivity. However, thermal conductivity of $0.1 \% \mathrm{CNC}$ nanofluids is slightly lower 
at temperature of $50{ }^{\circ} \mathrm{C}$ and $70{ }^{\circ} \mathrm{C}$ compare with base fluid. Figure 3 also illustrates that at any temperature thermal conductivity enhancement is not linear with continuous increment of volume concentration percentage of CNC nanoparticles. This similar phenomenon also observed by Wei, Zou and Li [51]. They found thermal conductivity enhancement is not even with increased volume concentration at a temperature of $20^{\circ} \mathrm{C}$. Ramachandran et al., [52] studied the thermal properties of water-ethylene glycol based CNC nanofluids and found addition of CNC nanoparticles can improve thermal conductivity and viscosity as well. It was also observed that the increasing temperature enhances thermal conductivity of CNC nanofluids. Thermal conductivity enhancement pattern can be discussed in accordance with the theory of Brownian motion. The collision between particles strengthened at higher temperature generating an increment of Brownian diffusion which reinforces the enhancement of thermal conductivity.

\subsection{Dynamic Viscosity Analysis of CNC Nanofluids}

Initially the viscosity of base fluid (60: $40 \mathrm{~W}: \mathrm{EG}$ ) measured and afterwards viscosity of nanofluids with different volume concentrations $(0.1 \%, 0.3 \%$ and $0.5 \%)$ determined at four distinct temperatures such as $30^{\circ}, 50^{\circ}, 70^{\circ}$ and $80^{\circ} \mathrm{C}$. Experimental viscosity results are shown in Figure 4. Here viscosity increases with increases in volume fractions and decreases when the temperature increased. The maximum value of viscosity found at $30{ }^{\circ} \mathrm{C}$ for $0.3 \%$ volume concentration and the minimum value observed at $80{ }^{\circ} \mathrm{C}$ for $0.1 \%$ volume concentration of CNC nanofluids.

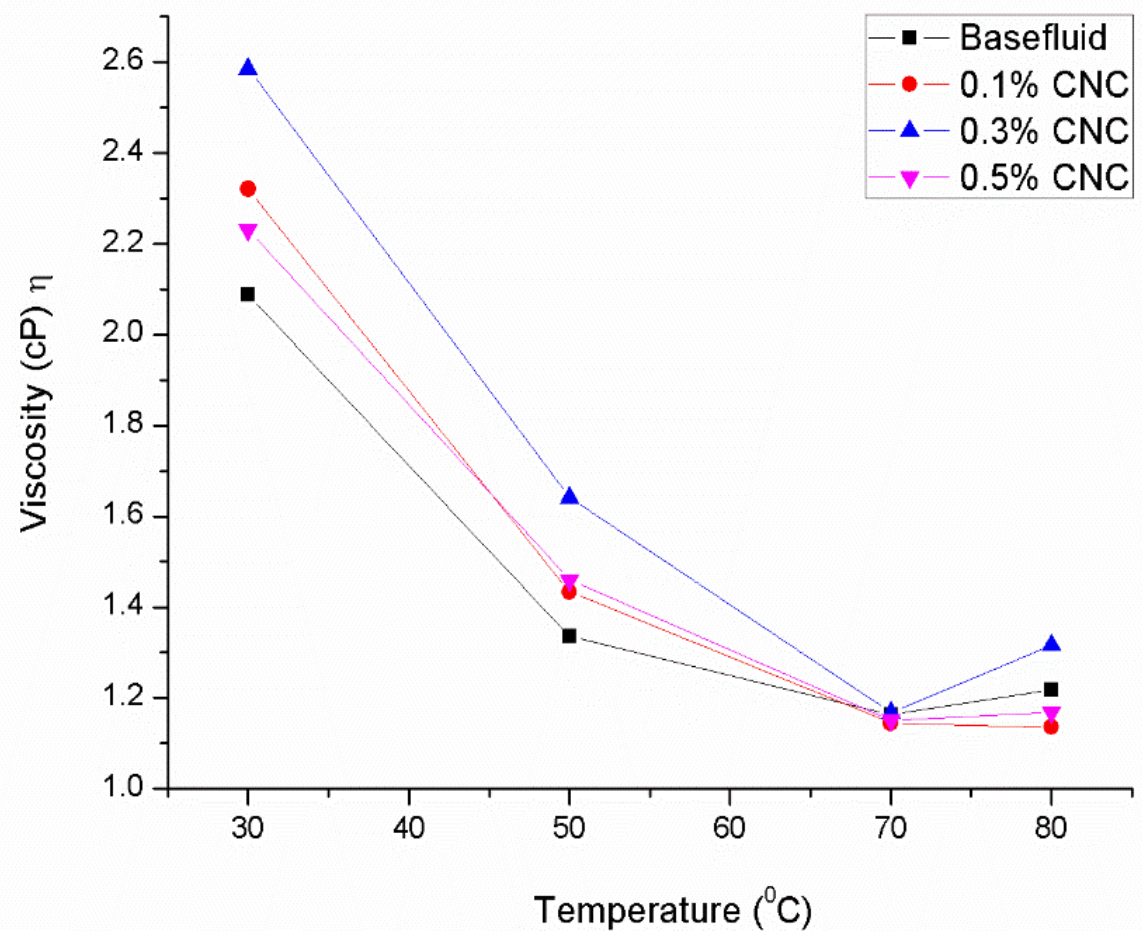

Fig. 4. Temperature dependence of viscosity of CNC nanofluids

Surprisingly viscosity of $0.5 \% \mathrm{CNC}$ nanofluid is lower than $0.3 \% \mathrm{CNC}$ nanofluid at $30{ }^{\circ} \mathrm{C}$ as shown in Figure 4, although this viscosity value of CNC nanofluids is higher comparing with base fluid. The viscosity trend of $0.3 \%$ and $0.5 \%$ CNC nanofluids along with base fluid exhibit upward trend at 80 ${ }^{\circ} \mathrm{C}$; although viscosity trend of nanofluids and base fluid is downward with raising the temperature up to $70{ }^{\circ} \mathrm{C}$ and the trend supposed to be in the same direction as well. Perhaps this viscosity phenomenon in this study supports the recommendation of Nguyen et al., [53] viscosity of nanofluid 
study. According to Newtonian Fluid theory, shear stress $(\tau)$ and shear rate $(\gamma)$ is straight and viscosity remains constant as defined Newtonian fluid [54]. But in the present work, the behaviour of all fluids does not support this Newtonian Fluid theory, as Figure 5 illustrates the disrupted trend of viscosity of $0.1 \% \mathrm{CNC}$ nanofluids at $30^{\circ} \mathrm{C}$. This trend is similar for all kind of nanofluids and base fluid at $30{ }^{\circ} \mathrm{C}$ $50{ }^{\circ} \mathrm{C}, 70{ }^{\circ} \mathrm{C}$ and $80^{\circ} \mathrm{C}$ which specify as non-Newtonian flow behaviour of all fluids.

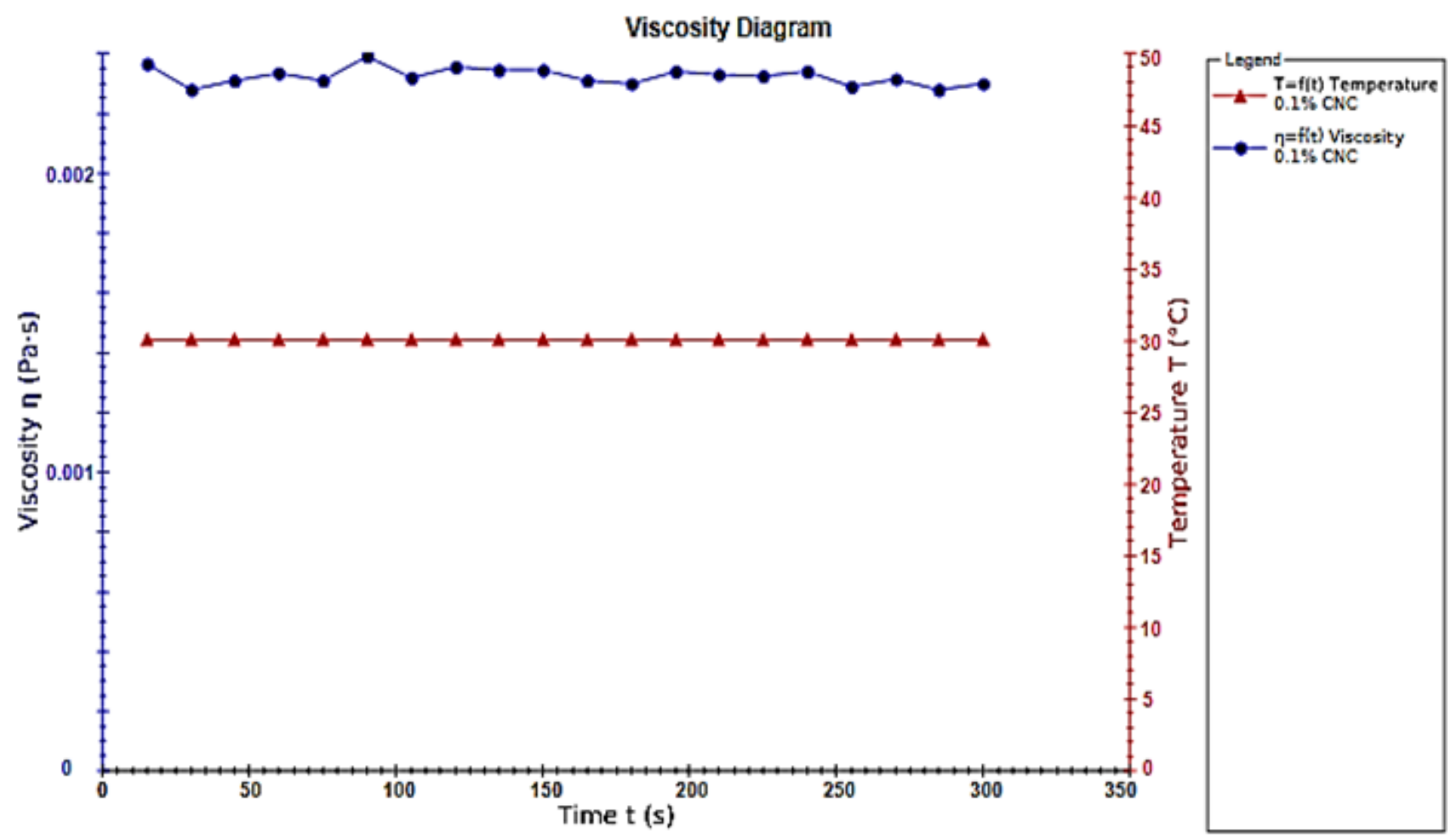

Fig. 5. Flow behaviour of $0.1 \% \mathrm{CNC}$ nanofluids

\subsection{Specific Heat Analysis of CNC Nanofluids}

Specific heat capacity characteristics of CNC nanofluids were studied here by Differential Scanning Calorimetry. The results of specific capacity of base fluid and CNC nanofluids are shown in Figure 6. Insufficient numerical and experimental studies had been conducted to determine the specific heat capacity of nanofluids at different temperature and volume concentrations. O'Hanley et al., [55] studied the specific heat capacity of nanofluids with various volume concentrations of different types of nanofluids (water-based alumina, silica, copper-oxide). They also used different size (diameter) of nanoparticles. They revealed specific heat capacity decreased due to increase of volume fractions of nanofluids. Singh et al., [56] concluded the specific heat decreases with increase of nanoparticles concentrations at room temperature and specific heat values is minimum at highest temperature for all nanofluids. Sekhar and Sharma [57] found that the increasing volume concentration of nanofluids (water based aluminium oxide) decline the specific heat capacity of nanofluids owing to increase of thermal diffusivity of nanofluids. They also mentioned the increment of temperature causes the decrement of effective specific heat capacity of nanofluids. On the other hand, Zhou and $\mathrm{Ni}$ [58] and Sekhar and Sharma [57] experimentally studied that effective specific heat corresponds to nanoparticles diameter. Effective specific heat improved owing to higher diameter of nanoparticles; as thermal conductivity increases with an increase in particle diameter. Figure 6 presents when the temperature increased, the specific heat of base fluid and CNC nanofluids 
decreased simultaneously. Furthermore, the adding of CNC nanoparticles in base fluid causes the loss of specific heat capacity. But in this study, there is no gradual degradation of specific heat capacity of nanofluids with augmentation of volume concentrations. Besides that, specific heat capacity of 0.3 $\%$ CNC nanofluids is higher than the base fluid; this result is contradictory comparing with other literatures. Moreover, $0.3 \%$ volume concentration of nanoparticles shows higher specific at $80{ }^{\circ} \mathrm{C}$ temperature than rest of the CNC nanofluids concentrations. Here among all other volume concentrations of $\mathrm{CNC}$ nanofluids, $0.5 \%$ performs the best result up to $70{ }^{\circ} \mathrm{C}$ temperature.

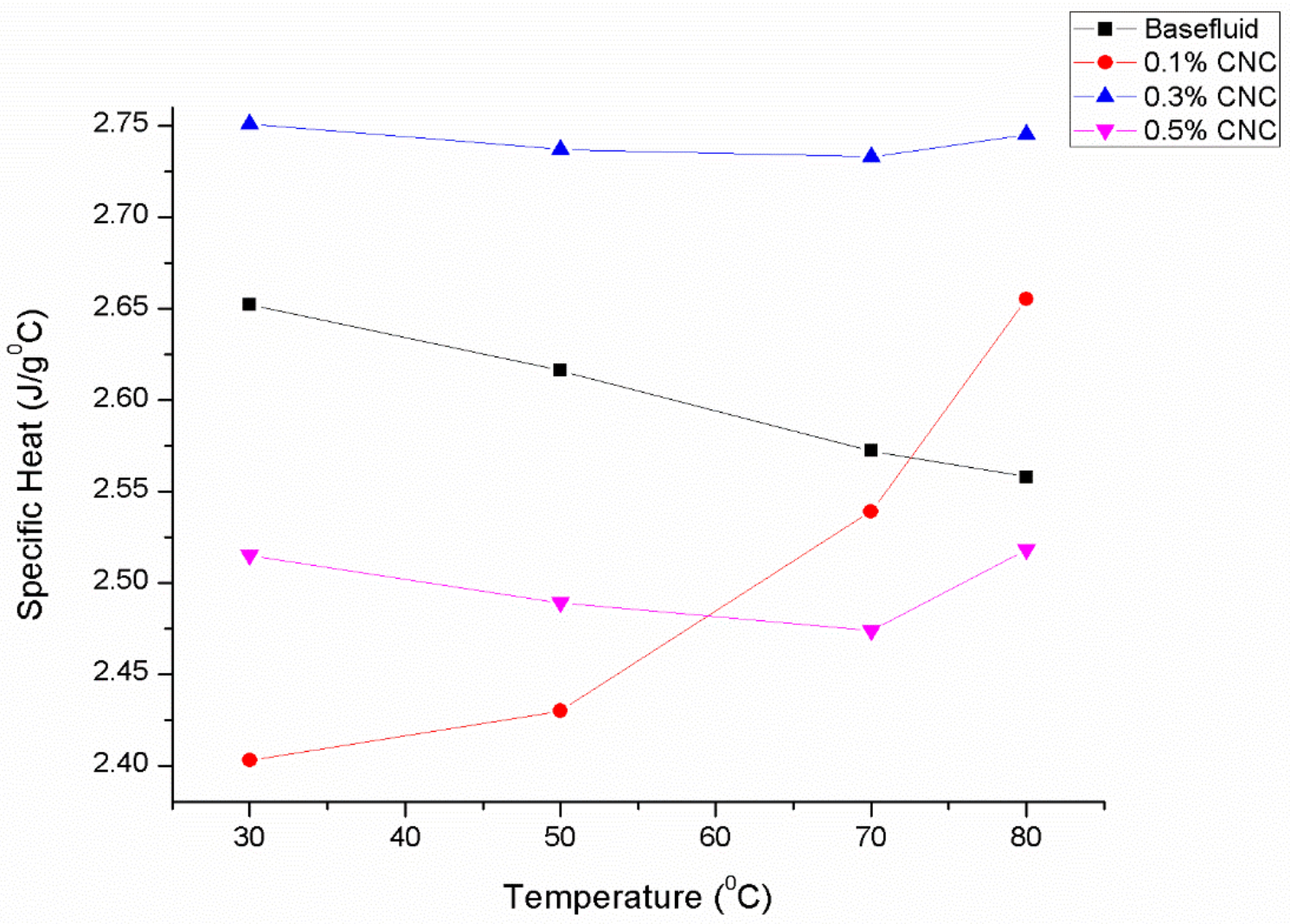

Fig. 6. Effect of temperature on specific heat of $\mathrm{CNC}$ nanofluids

\subsection{Density Measurement of CNC Nanofluids}

Generally, density of nanofluids is equivalent to the volume ratio of nano particles and base fluid. Base fluid performs an important role in the density of nanofluids. Density is also temperature sensitive characteristic of nanofluids. The increasing temperature decreases the density of nanofluids [59]. In this study, due to the deficiency (temperature) of equipment, density of nanofluid only measured at $20^{\circ} \mathrm{C}$ for base fluid and different volumetric concentrations of CNC nanofluids as shown in Figure 7.

The result of density of base fluid is in good agreement with ASHREE data and the deviation is only about $0.77 \%$. The theoretical density data of all kind of fluids shown in Table 2. Experimental and theoretical density data has deviation within $0.26 \%$ which determine a satisfactory agreement between these two types of density values of base fluid and nanofluids as presented in Figure 7. 


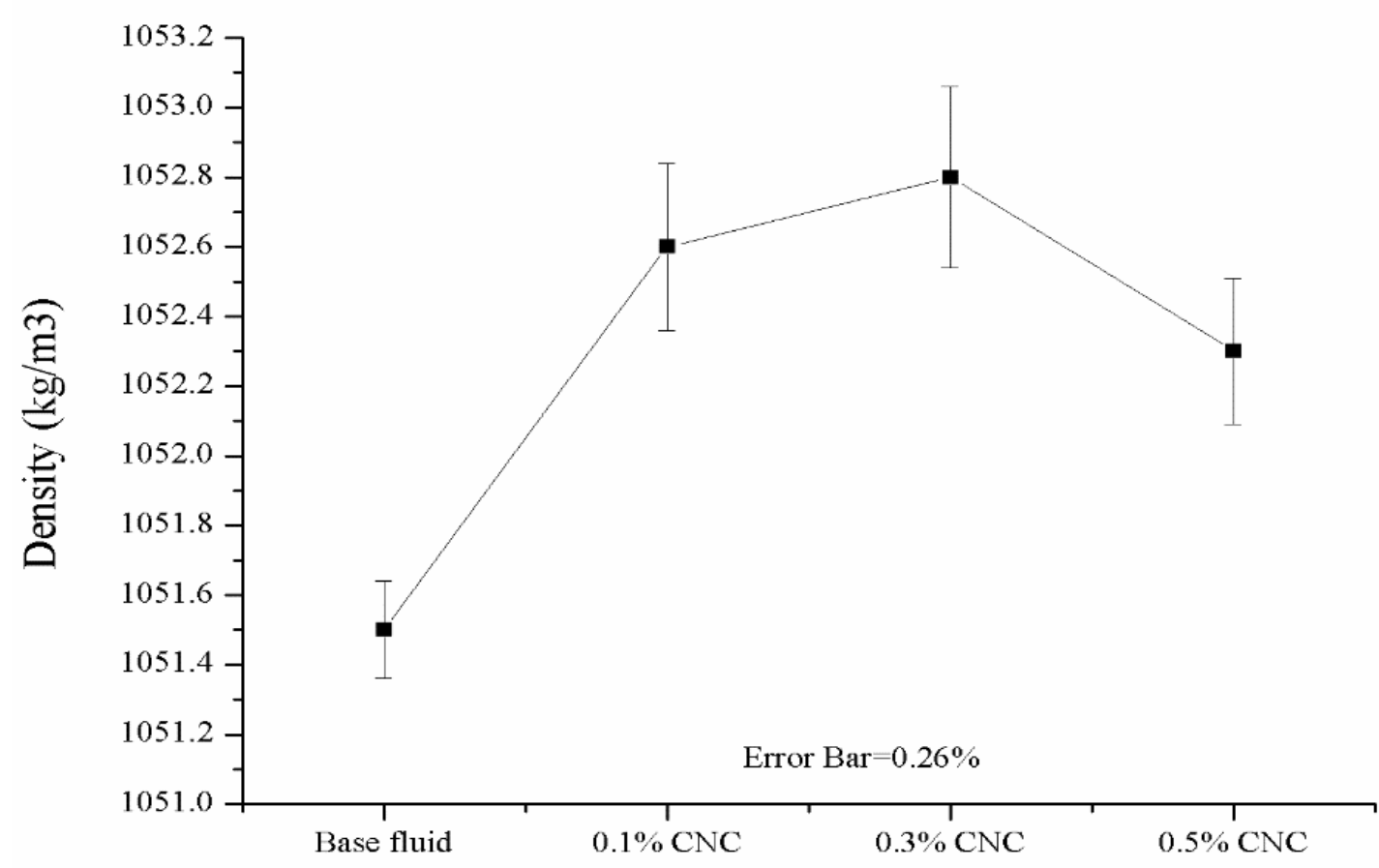

Base fluid and CNC nanofluids volume concentration

Fig. 7. Density measurement of base fluid and CNC nanofluids

Table 2

Theoretical density values of fluids

\begin{tabular}{ll}
\hline Items & Density $\left(\mathrm{kg} / \mathrm{m}^{3}\right)$ \\
\hline Base fluid (60: 40; W: EG) & $1050[60]$ \\
$0.1 \%$ CNC nanofluids & 1050 \\
$0.3 \%$ CNC nanofluids & 1050 \\
$0.5 \%$ CNC nanofluids & 1050 \\
\hline
\end{tabular}

\section{6 pH Analysis of CNC Nanofluids}

$\mathrm{pH}$ is one of the most important factors of nanofluids as the stability of nanofluids depends on it. The increment of thermal conductivity well depends on the stability and the state of surface charge of nanofluids [61-62]. The more difference between the $\mathrm{pH}$ of nanofluids and the $\mathrm{pH}$ of isoelectric point (IEP) causes more stable nanofluids and increases efficiency as well [63-64]. Literatures stated $\mathrm{pH}$ value of different nanoparticles are not equivalent and has dependency on temperature, volume concentration and particle size [62-63, 65]. Jia-Fei et al., [66] revealed that the small size of nanoparticles performs significantly fluctuations of $\mathrm{pH}$ values from 5 to 7 . Moreover, low $\mathrm{pH}$ value performs good heat transfer property of nanofluids. Because in low pH condition, hydration forces among the particles increases in the suspension which results the mobility enhancement of nanofluids in the suspension to lead the heat transport process [67]. On the contrary, Goudarzi et al., [64] experimentally concluded that higher $\mathrm{pH}$ values of nanofluids increases more efficiency than lower $\mathrm{pH}$ values. Figure 8 demonstrates that $\mathrm{pH}$ values of $0.1 \%$ vol. concentration of $\mathrm{CNC}$ nanofluids are decreased than base fluids. On the other hand, $\mathrm{pH}$ value of $0.3 \% \mathrm{CNC}$ nanofluid at $30{ }^{\circ} \mathrm{C}$ and 50 ${ }^{\circ} \mathrm{C}$ is equal with base fluid as well as $\mathrm{pH}$ value of $0.5 \% \mathrm{CNC}$ nanofluids increased at $30{ }^{\circ} \mathrm{C}$ and $70{ }^{\circ} \mathrm{C}$ comparing with base fluid. But $\mathrm{pH}$ values of all $\mathrm{CNC}$ nanofluids decrease at $80{ }^{\circ} \mathrm{C}$ temperature. 


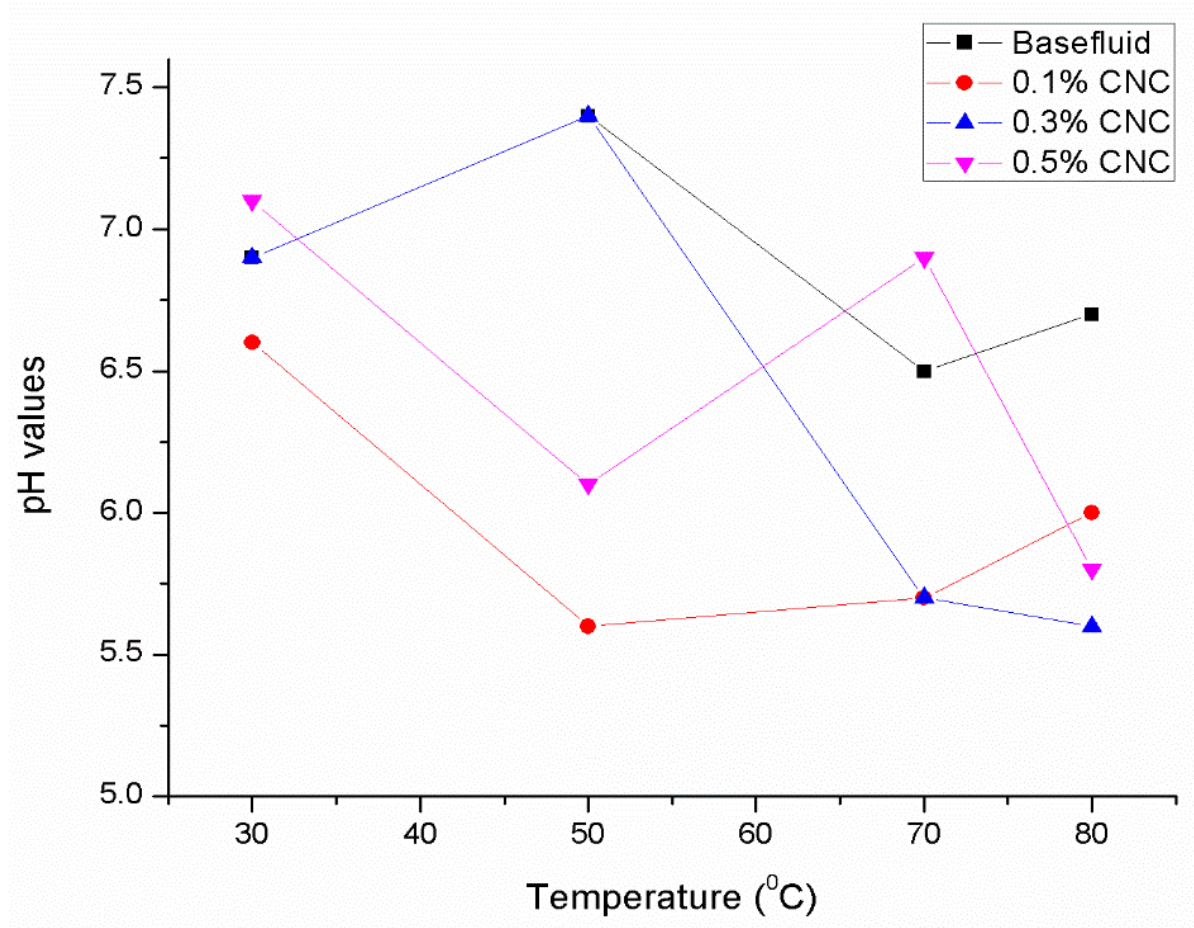

Fig. 8. $\mathrm{pH}$ values of different concentration of CNC nanofluids

\section{Conclusions}

Throughout the research work, stability of CNC nanofluids was very good and no sedimentation occurred; thermal conductivity has been increased for the addition of CNC nanoparticles to the aqueous ethylene glycol (60: 40; W: EG) base fluid. $0.3 \%$ volume concentration of CNC nanofluids maintained the gradual increment of thermal conductivity within this temperature range, maximum thermal conductivity achieved at $80^{\circ} \mathrm{C}$ and the improvement was of about $25 \%$. Experimental results of viscosity showed the decrement with increasing the temperature of CNC nanofluids. In case of specific heat, $0.5 \%$ volume concentration performed excellent results than other concentrations and base fluid up to $70{ }^{\circ} \mathrm{C}$ temperature. The resultant data of density of CNC nanofluids were in good agreement with theoretical data and finally $\mathrm{pH}$ values of CNC nanofluids were in range of 5 to 7.5 confined with in this temperature range. However, some experimental values show the contradictory results compared with CNC nanofluids related previous literatures. The resultant data of thermalphysical properties of crystal nanocellulose nanofluids show the interesting and promising approach in respect of thermal engineering applications.

\section{Acknowledgement}

The authors are grateful to acknowledge University Malaysia Pahang (UMP) for Grant RDU 180328 and Bangabandhu Science and Technology Fellowship Trust (Bangladesh) to provide laboratory facilities and financial assistance to conclude the research works.

\section{References}

[1] Brutschin, Elina, and Andreas Fleig. "Innovation in the energy sector-The role of fossil fuels and developing economies." Energy Policy 97 (2016): 27-38. https://doi.org/10.1016/i.enpol.2016.06.041

[2] Bell, Sandra, Ellis Judson, Harriet Bulkeley, Gareth Powells, Klara Anna Capova, and David Lynch. "Sociality and electricity in the United Kingdom: the influence of household dynamics on everyday consumption." Energy research \& social science 9 (2015): 98-106. 
https://doi.org/10.1016/j.erss.2015.08.027

[3] Costa, M. Teresa, Jose Garcia-Quevedo, and Elisa Trujillo-Baute. "Challenges for R\&D and innovation in energy." Energy Policy, 2015, vol. 83, num. August, p. 193-196 (2015).

https://doi.org/10.1016/i.enpol.2015.04.012

[4] Hasanuzzaman, M., N. A. Rahim, Rahman Saidur, and S. N. Kazi. "Energy savings and emissions reductions for rewinding and replacement of industrial motor." Energy 36, no. 1 (2011): 233-240. https://doi.org/10.1016/i.energy.2010.10.046

[5] Peng, Lihong, Yiting Zhang, Yejun Wang, Xiaoling Zeng, Najun Peng, and Ang Yu. "Energy efficiency and influencing factor analysis in the overall Chinese textile industry." Energy 93 (2015): 1222-1229.

https://doi.org/10.1016/i.energy.2015.09.075

[6] Yusof, Siti Nurul Akmal, Yutaka Asako, Mohammad Faghri, Lit Ken Tan, Nor Azwadi Bin Che Sidik, and Wan Mohd Arif Bin Aziz Japar. "Energy equation of swirling flow in a cylindrical container." International Communications in Heat and Mass Transfer 108 (2019): 104288.

https://doi.org/10.1016/j.icheatmasstransfer.2019.104288

[7] Birol, Fatih. "World energy outlook." Paris: International Energy Agency 23, no. 4 (2008): 329.

[8] York, Richard. "Do alternative energy sources displace fossil fuels?." Nature Climate Change 2, no. 6 (2012): 441443.

https://doi.org/10.1038/nclimate1451

[9] Adra, Friederike. Renewable Energy: An Eco-friendly Alternative?. Friedrich-Ebert-Stiftung, Ghana Office, 2014.

[10] Rosen, Marty. "Creating Sustainable Communities. A Guide for Developers and Communities." New Jersey Department of Environmental Protection, office of planning and sustainable communities (2007).

[11] Kuno, M.K., Introduction to Nanoscience and Nanotechnology: A Workbook, 2005.

[12] Panchal, K. D. "Nanofluid: A Tool to Increase the Efficiency of Solar Collector." International Journal for InnovativeEngineering and Technology 5, no. 2 (2015): 350-366.

[13] Abubakar, Saidu Bello, Nor Azwadi Che Sidik, and Siti Nurul Akmal Yusof. "Measurement of Fluid Flow and Heat Transfer Performance in Rectangular Microchannel using Pure Water and Fe3O4-H2O Nanofluid." Journal of Advanced Research in Applied Mechanics 68, no. 1 (2020): 9-21. https://doi.org/10.37934/aram.68.1.921

[14] Nagarajan, P. K., J. Subramani, S. Suyambazhahan, and Ravishankar Sathyamurthy. "Nanofluids for solar collector applications: a review." Energy Procedia 61 (2014): 2416-2434.

https://doi.org/10.1016/j.egypro.2014.12.017

[15] Mahian, Omid, Ali Kianifar, Clement Kleinstreuer, Al-Nimr Moh'd A, loan Pop, Ahmet Z. Sahin, and Somchai Wongwises. "A review of entropy generation in nanofluid flow." International Journal of Heat and Mass Transfer 65 (2013): 514-532. https://doi.org/10.1016/i.ijheatmasstransfer.2013.06.010

[16] Fubini, Bice, and Andrea Hubbard. "Reactive oxygen species (ROS) and reactive nitrogen species (RNS) generation by silica in inflammation and fibrosis." Free Radical Biology and Medicine 34, no. 12 (2003): 1507-1516.

https://doi.org/10.1016/S0891-5849(03)00149-7

[17] Huang, Yue-Wern, Chi-heng Wu, and Robert S. Aronstam. "Toxicity of transition metal oxide nanoparticles: recent insights from in vitro studies." Materials 3, no. 10 (2010): 4842-4859. https://doi.org/10.3390/ma3104842

[18] Buzea, Cristina, Ivan I. Pacheco, and Kevin Robbie. "Nanomaterials and nanoparticles: sources and toxicity." Biointerphases 2, no. 4 (2007): MR17-MR71. https://doi.org/10.1116/1.2815690

[19] Dietz, Karl-Josef, and Simone Herth. "Plant nanotoxicology." Trends in plant science 16, no. 11 (2011): 582-589. https://doi.org/10.1016/j.tplants.2011.08.003

[20] Hossain, Zahed, Ghazala Mustafa, Katsumi Sakata, and Setsuko Komatsu. "Insights into the proteomic response of soybean towards Al2O3, ZnO, and Ag nanoparticles stress." Journal of hazardous materials 304 (2016): 291-305. https://doi.org/10.1016/j.jhazmat.2015.10.071

[21] Zhou, Y. M., S. Y. Fu, L. M. Zheng, and H. Y. Zhan. "Effect of nanocellulose isolation techniques on the formation of reinforced poly (vinyl alcohol) nanocomposite films." Express Polymer Letters 6, no. 10 (2012). https://doi.org/10.3144/expresspolymlett.2012.85

[22] Abitbol, Tiffany, Amit Rivkin, Yifeng Cao, Yuval Nevo, Eldho Abraham, Tal Ben-Shalom, Shaul Lapidot, and Oded Shoseyov. "Nanocellulose, a tiny fiber with huge applications." Current opinion in biotechnology 39 (2016): 76-88. https://doi.org/10.1016/i.copbio.2016.01.002 
[23] Theivasanthi, T., FL Anne Christma, Adeleke Joshua Toyin, Subash CB Gopinath, and Ramanibai Ravichandran. "Synthesis and characterization of cotton fiber-based nanocellulose." International journal of biological macromolecules 109 (2018): 832-836.

https://doi.org/10.1016/j.ijbiomac.2017.11.054

[24] Brinchi, L., F. Cotana, E. Fortunati, and J. M. Kenny. "Production of nanocrystalline cellulose from lignocellulosic biomass: technology and applications." Carbohydrate polymers 94, no. 1 (2013): 154-169. https://doi.org/10.1016/i.carbpol.2013.01.033

[25] Mondal, Subrata. "Preparation, properties and applications of nanocellulosic materials." Carbohydrate polymers 163 (2017): 301-316. https://doi.org/10.1016/i.carbpol.2016.12.050

[26] Cho, Mi-Jung, and Byung-Dae Park. "Tensile and thermal properties of nanocellulose-reinforced poly (vinyl alcohol) nanocomposites." Journal of Industrial and Engineering Chemistry 17, no. 1 (2011): 36-40. https://doi.org/10.1016/j.jiec.2010.10.006

[27] Heggset, Ellinor B., Gary Chinga-Carrasco, and Kristin Syverud. "Temperature stability of nanocellulose dispersions." Carbohydrate polymers 157 (2017): 114-121.

https://doi.org/10.1016/j.carbpol.2016.09.077

[28] Dufresne, Alain. "Nanocellulose: a new ageless bionanomaterial." Materials today 16, no. 6 (2013): $220-227$. https://doi.org/10.1016/i.mattod.2013.06.004

[29] Sundar, L. Syam, E. Venkata Ramana, M. P. F. Graça, Manoj K. Singh, and Antonio CM Sousa. "Nanodiamond-Fe304 nanofluids: preparation and measurement of viscosity, electrical and thermal conductivities." International Communications in Heat and Mass Transfer 73 (2016): 62-74.

https://doi.org/10.1016/j.icheatmasstransfer.2016.02.013

[30] Kadirgama, K., K. Anamalai, K. Ramachandran, D. Ramasamy, M. Samykano, A. Kottasamy, and M. M. Rahman. "Thermal analysis of SUS 304 stainless steel using ethylene glycol/nanocellulose-based nanofluid coolant." The International Journal of Advanced Manufacturing Technology 97, no. 5-8 (2018): 2061-2076. https://doi.org/10.1007/s00170-018-2061-3

[31] Ramachandran, K., K. Kadirgama, D. Ramasamy, W. H. Azmi, and F. Tarlochan. "Investigation on effective thermal conductivity and relative viscosity of cellulose nanocrystal as a nanofluidic thermal transport through a combined experimental-Statistical approach by using Response Surface Methodology." Applied Thermal Engineering 122 (2017): 473-483.

https://doi.org/10.1016/j.applthermaleng.2017.04.049

[32] Blue Goose Biorefineries Inc. CNC Product Characteristics. n.d. [cited 201822 May]; Available from: https://bluegoosebiorefineries.com/product/.

[33] Chiam, H. W., W. H. Azmi, N. A. Usri, Rizalman Mamat, and N. M. Adam. "Thermal conductivity and viscosity of Al2O3 nanofluids for different based ratio of water and ethylene glycol mixture." Experimental Thermal and Fluid Science 81 (2017): 420-429.

https://doi.org/10.1016/j.expthermflusci.2016.09.013

[34] Esfe, Mohammad Hemmat, Arash Karimipour, Wei-Mon Yan, Mohammad Akbari, Mohammad Reza Safaei, and Mahidzal Dahari. "Experimental study on thermal conductivity of ethylene glycol based nanofluids containing Al2O3 nanoparticles." International Journal of Heat and Mass Transfer 88 (2015): 728-734. https://doi.org/10.1016/i.ijheatmasstransfer.2015.05.010

[35] Samylingam, L., K. Anamalai, K. Kadirgama, M. Samykano, D. Ramasamy, M. M. Noor, G. Najafi, M. M. Rahman, Hong Wei Xian, and Nor Azwadi Che Sidik. "Thermal analysis of cellulose nanocrystal-ethylene glycol nanofluid coolant." International Journal of Heat and Mass Transfer 127 (2018): 173-181.

https://doi.org/10.1016/i.ijheatmasstransfer.2018.07.080

[36] Azmi, W. H., K. V. Sharma, P. K. Sarma, Rizalman Mamat, and G. Najafi. "Heat transfer and friction factor of water based $\mathrm{TiO} 2$ and $\mathrm{SiO} 2$ nanofluids under turbulent flow in a tube." International Communications in Heat and Mass Transfer 59 (2014): 30-38. https://doi.org/10.1016/j.icheatmasstransfer.2014.10.007

[37] Azmi, W. H., K. Abdul Hamid, Rizalman Mamat, K. V. Sharma, and M. S. Mohamad. "Effects of working temperature on thermo-physical properties and forced convection heat transfer of TiO2 nanofluids in water-Ethylene glycol mixture." Applied Thermal Engineering 106 (2016): 1190-1199.

https://doi.org/10.1016/i.applthermaleng.2016.06.106

[38] Ravikumar, Satya V., Krishnayan Haldar, Jay M. Jha, Samarshi Chakraborty, Ishita Sarkar, Surjya K. Pal, and Sudipto Chakraborty. "Heat transfer enhancement using air-atomized spray cooling with water-Al2O3 nanofluid." International Journal of Thermal Sciences 96 (2015): 85-93.

https://doi.org/10.1016/i.ijthermalsci.2015.04.012 
[39] Arulprakasajothi, M., K. Elangovan, K. HemaChandra Reddy, and S. Suresh. "Heat transfer study of water-based nanofluids containing titanium oxide nanoparticles." Materials Today: Proceedings 2, no. 4-5 (2015): 3648-3655. https://doi.org/10.1016/i.matpr.2015.07.123

[40] O'neill, M. J. "Measurement of Specific Heat Functions by Differential Scanning Calorimetry." Analytical chemistry 38, no. 10 (1966): 1331-1336. https://doi.org/10.1021/ac60242a011

[41] Kodre, K. V., S. R. Attarde, P. R. Yendhe, R. Y. Patil, and V. U. Barge. "Differential scanning calorimetry: A review." Research and Reviews: Journal of Pharmaceutical Analysis 3, no. 3 (2014): 11-22.

[42] Shin, Donghyun, and Debjyoti Banerjee. "Enhancement of specific heat capacity of high-temperature silicananofluids synthesized in alkali chloride salt eutectics for solar thermal-energy storage applications." International journal of heat and mass transfer 54, no. 5-6 (2011): 1064-1070. https://doi.org/10.1016/j.ijheatmasstransfer.2010.11.017

[43] Slough, Carlton G., and Nathan D. Hesse. "High Precision Heat Capacity Measurements of Metals by Modulated DSC ${ }^{\circledR} . "$ In Proc NATAS Annu Conf Therm Anal Appl, vol. 34, p. 160. 2006.

[44] Said, Z., M. A. Sabiha, Rahman Saidur, A. Hepbasli, Nasrudin Abd Rahim, Saad Mekhilef, and T. A. Ward. "Performance enhancement of a flat plate solar collector using titanium dioxide nanofluid and polyethylene glycol dispersant." Journal of Cleaner Production 92 (2015): 343-353. https://doi.org/10.1016/j.jclepro.2015.01.007

[45] Said, Z., A. Kamyar, and R. Saidur. "Experimental investigation on the stability and density of TiO2, Al2O3, SiO2 and TiSiO4." In IOP conference series: earth and environmental science, vol. 16, no. 1, p. 012002. IOP Publishing, 2013. https://doi.org/10.1088/1755-1315/16/1/012002

[46] Mahian, Omid, Ali Kianifar, and Somchai Wongwises. "Dispersion of ZnO nanoparticles in a mixture of ethylene glycol-water, exploration of temperature-dependent density, and sensitivity analysis." Journal of Cluster Science 24, no. 4 (2013): 1103-1114. https://doi.org/10.1007/s10876-013-0601-4

[47] Li, X. F., D. S. Zhu, X. J. Wang, N. Wang, J. W. Gao, and H. Li. "Thermal conductivity enhancement dependent pH and chemical surfactant for Cu-H2O nanofluids." Thermochimica Acta 469, no. 1-2 (2008): 98-103. https://doi.org/10.1016/i.tca.2008.01.008

[48] Xian-Ju, Wang, and Li Xin-Fang. "Influence of pH on nanofluids' viscosity and thermal conductivity." Chinese Physics Letters 26, no. 5 (2009): 056601. https://doi.org/10.1088/0256-307X/26/5/056601

[49] Korada, Viswanatha Sharma, and Nor Hisham B. Hamid, eds. Engineering Applications of Nanotechnology: From Energy to Drug Delivery. Springer, 2017. https://doi.org/10.1007/978-3-319-29761-3

[50] Sarsam, Wail Sami, Ahmad Amiri, Mohd Nashrul Mohd Zubir, Hooman Yarmand, S. N. Kazi, and A. Badarudin. "Stability and thermophysical properties of water-based nanofluids containing triethanolamine-treated graphene nanoplatelets with different specific surface areas." Colloids and Surfaces A: Physicochemical and Engineering Aspects 500 (2016): 17-31. https://doi.org/10.1016/i.colsurfa.2016.04.016

[51] Wei, Baojie, Changjun Zou, and Xiaoke Li. "Experimental investigation on stability and thermal conductivity of diathermic oil based TiO2 nanofluids." International Journal of Heat and Mass Transfer 104 (2017): 537-543. https://doi.org/10.1016/i.ijheatmasstransfer.2016.08.078

[52] Ramachandran, Kaaliarasan, A. M. Hussein, K. Kadirgama, D. Ramasamy, W. H. Azmi, F. Tarlochan, and G. Kadirgama. "Thermophysical properties measurement of nano cellulose in ethylene glycol/water." Applied Thermal Engineering 123 (2017): 1158-1165. https://doi.org/10.1016/j.applthermaleng.2017.05.067

[53] Nguyen, C. T., F. Desgranges, N. Galanis, G. Roy, Thierry Maré, S. Boucher, and H. Angue Mintsa. "Viscosity data for Al2O3-water nanofluid-hysteresis: is heat transfer enhancement using nanofluids reliable?." International journal of thermal sciences 47, no. 2 (2008): 103-111.

https://doi.org/10.1016/i.ijthermalsci.2007.01.033

[54] Bagnold, Ralph Alger. "Experiments on a gravity-free dispersion of large solid spheres in a Newtonian fluid under shear." Proceedings of the Royal Society of London. Series A. Mathematical and Physical Sciences 225, no. 1160 (1954): 49-63. https://doi.org/10.1098/rspa.1954.0186

[55] O'Hanley, Harry, Jacopo Buongiorno, Thomas McKrell, and Lin-wen Hu. "Measurement and model validation of nanofluid specific heat capacity with differential scanning calorimetry." Advances in Mechanical Engineering 4 (2012): 181079. 
https://doi.org/10.1155/2012/181079

[56] Singh, Rabesh Kumar, Anuj Kumar Sharma, Amit Rai Dixit, Amitava Mandal, and Arun Kumar Tiwari. "Experimental investigation of thermal conductivity and specific heat of nanoparticles mixed cutting fluids." Materials Today: Proceedings 4, no. 8 (2017): 8587-8596. https://doi.org/10.1016/i.matpr.2017.07.206

[57] Sekhar, Y. Raja, and K. V. Sharma. "Study of viscosity and specific heat capacity characteristics of water-based Al2O3 nanofluids at low particle concentrations." Journal of experimental Nanoscience 10, no. 2 (2015): 86-102. https://doi.org/10.1080/17458080.2013.796595

[58] Zhou, Sheng-Qi, and Rui Ni. "Measurement of the specific heat capacity of water-based Al 203 nanofluid." Applied Physics Letters 92, no. 9 (2008): 093123. https://doi.org/10.1063/1.2890431

[59] Vajjha, R. S., D. K. Das, and B. M. Mahagaonkar. "Density measurement of different nanofluids and their comparison with theory." Petroleum Science and Technology 27, no. 6 (2009): 612-624. https://doi.org/10.1080/10916460701857714

[60] Fogg, Edward T., A. Norman Hixson, and A. Ralph Thompson. "Densities and refractive indexes for ethylene glycolwater solutions." Analytical Chemistry 27, no. 10 (1955): 1609-1611. https://doi.org/10.1021/ac60106a033

[61] Huang, Jin, Xianju Wang, Qiong Long, Xueyi Wen, Yunjin Zhou, and Liming Li. "Influence of pH on the stability characteristics of nanofluids." In 2009 Symposium on Photonics and Optoelectronics, pp. 1-4. IEEE, 2009. https://doi.org/10.1109/SOPO.2009.5230102

[62] Adio, Saheed A., Mohsen Sharifpur, and Josua P. Meyer. "Factors affecting the $\mathrm{pH}$ and electrical conductivity of MgO-ethylene glycol nanofluids." Bulletin of Materials Science 38, no. 5 (2015): 1345-1357. https://doi.org/10.1007/s12034-015-1020-y

[63] Yousefi, Tooraj, Farzad Veisy, Ehsan Shojaeizadeh, and Sirus Zinadini. "An experimental investigation on the effect of MWCNT-H2O nanofluid on the efficiency of flat-plate solar collectors." Experimental Thermal and Fluid Science 39 (2012): 207-212. https://doi.org/10.1016/i.expthermflusci.2012.01.025

[64] Goudarzi, K., F. Nejati, E. Shojaeizadeh, and SK Asadi Yousef-abad. "Experimental study on the effect of pH variation of nanofluids on the thermal efficiency of a solar collector with helical tube." Experimental Thermal and Fluid Science 60 (2015): 20-27. https://doi.org/10.1016/j.expthermflusci.2014.07.015

[65] Konakanchi, Hanumantharao, Ravikanth S. Vajjha, Godwin A. Chukwu, and Debendra K. Das. "Measurements of pH of three nanofluids and development of new correlations." Heat Transfer Engineering 36, no. 1 (2015): 81-90. https://doi.org/10.1080/01457632.2014.906286

[66] Jia-Fei, Zhao, Luo Zhong-Yang, Ni Ming-Jiang, and Cen Ke-Fa. "Dependence of nanofluid viscosity on particle size and pH value." Chinese Physics Letters 26, no. 6 (2009): 066202. https://doi.org/10.1088/0256-307X/26/6/066202

[67] Xie, Huaqing, Jinchang Wang, Tonggeng Xi, Yan Liu, Fei Ai, and Qingren Wu. "Thermal conductivity enhancement of suspensions containing nanosized alumina particles." Journal of applied physics 91, no. 7 (2002): 4568-4572. https://doi.org/10.1063/1.1454184 